\title{
Optimize the dose of oxaliplatin for locally advanced rectal cancer treated with neoadjuvant chemoradiotherapy followed by radical surgery and adjuvant chemotherapy
}

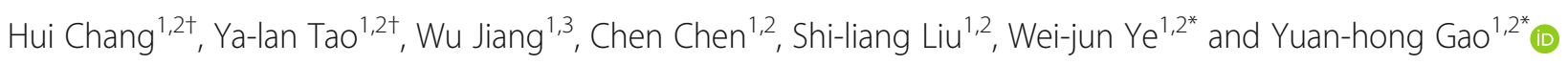

\begin{abstract}
Background: Addition of oxaliplatin to capecitabine remains controversial for locally advanced rectal cancer (LARC). And cumulative oxaliplatin dose (COD) varied among clinical trials showing different therapeutic effects of this regimen. The objective of this study was to explore how COD affected tumor metastasis and patient survival.

Methods: Totally 388 patients diagnosed with stage cII-III rectal cancer and treated with neoadjuvant chemoradiotherapy followed by radical surgery plus adjuvant chemotherapy were consecutively enrolled into this study and retrospectively reviewed. After grouping by total chemotherapy cycle (TCC), influences of COD on adverse effects and patients' survivals were analyzed in each group. Univariate and multivariate survival analyses were performed through Kaplan-Meier approach and COX proportional hazards model, respectively. Age, gender, anemia, differentiation, carcinoembryonic antigen, carbohydrate antigen 19-9, pretreatment clinical stage and postsurgical pathologic stage were used as covariates.

Results: COD $<460 \mathrm{mg} / \mathrm{m}^{2}$ emerged as an independent predictor of poorer overall, metastasis-free and disease-free survivals, in patients treated with TCC $\leq 7$. The hazard ratios were 1.972, 1.763 and 1.637 ( $P$ values were $0.021,0.028$ and 0.041), respectively. But it was note-worthy that COD $\geq 460 \mathrm{mg} / \mathrm{m}^{2}$ increased incidence of acute toxicities from 38.4 to $70.8 \%$ $(P<0.001)$. And in patients treated with TCC $\geq 8$, COD failed to be a prognosticator.

Conclusions: For LARC patients treated with insufficient TCC $(\leq 7)$, oxaliplatin of $\geq 460 \mathrm{mg} / \mathrm{m}^{2}$ might be needed to improve survival, though it might resulted in more acute toxicities.
\end{abstract}

Keywords: Rectal neoplasms, Oxaliplatin, Distant metastasis, Survival

\footnotetext{
*Correspondence: yewj1968@126.com; gaoyh1969@126.com

${ }^{\dagger}$ Hui Chang and Ya-lan Tao are co-first authors and contributed equally to this work.

'Department of Radiation Oncology, Sun Yat-sen University Cancer Center, Guangzhou, China

Full list of author information is available at the end of the article
}

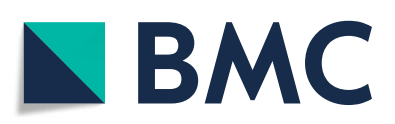

(- The Author(s). 2020 Open Access This article is licensed under a Creative Commons Attribution 4.0 International License, which permits use, sharing, adaptation, distribution and reproduction in any medium or format, as long as you give appropriate credit to the original author(s) and the source, provide a link to the Creative Commons licence, and indicate if changes were made. The images or other third party material in this article are included in the article's Creative Commons licence, unless indicated otherwise in a credit line to the material. If material is not included in the article's Creative Commons licence and your intended use is not permitted by statutory regulation or exceeds the permitted use, you will need to obtain permission directly from the copyright holder. To view a copy of this licence, visit http://creativecommons.org/licenses/by/4.0/. The Creative Commons Public Domain Dedication waiver (http://creativecommons.org/publicdomain/zero/1.0/) applies to the data made available in this article, unless otherwise stated in a credit line to the data. 


\section{Background}

Rectal cancer accounts for $56.7 \%$ of colorectal cancer, which is the 3rd most common malignancies in China $[1,2]$. Currently, the standard mode to manage locally advanced rectal cancer (LARC) is neoadjuvant chemoradiotherapy (NACRT) followed by radical surgery and adjuvant chemotherapy (ACT) [3]. In spite of ideal local control, distant metastasis (DM) will finally occur in $20.6 \%$ of LARC patients [4]. Namely, DM is the primary style of treatment failure in these patients. It is essential to reduce DM, so as to improve prognosis of LARC.

Chemotherapy is one of the most effective treatments to eliminate DM of solid tumors. For LARC, capecitabine plus oxaliplatin (CAPEOX) is one of the commonly used chemotherapy regimens. Yet, clinical values of oxaliplatin still remain controversial [5]. Several phase 3 trials showed that neither improved local control nor survival benefit was attained through adding oxaliplatin to fluorouracil or capecitabine [6-8]. By contrast, different results were seen in the recent $\mathrm{CAO} / \mathrm{ARO} / \mathrm{AIO}-04$ trial. Oxaliplatin led to a $4 \%$ elevation of both pathological complete response (pCR) rate and 3-year diseasefree survival (DFS). When chemotherapy intensity was taken into account, the CAO/ARO/AIO-04 trial had an obviously higher cumulative oxaliplatin dose (COD) than prior studies (1000 vs. $250-360 \mathrm{mg} / \mathrm{m}^{2}$ ) [9]. So we speculated that treatment effects of oxaliplatin might depend on COD.

On the other side, oxaliplatin could lead to a series of toxicities, especially acute and late peripheral neuropathy (PN). PN is a dose-limit toxicity because it lacks efficacious therapeutic methods. And it is reported that the incidence of $\mathrm{PN}$ increases dramatically when COD exceeded $780 \mathrm{mg} / \mathrm{m}^{2}$, which is often used as an upper limit of COD [10]. Here we conducted a study to optimize COD for LARC patients, within the tolerable dose range. Since the National Comprehensive Cancer Network recommended the total cycle of CAPEOX chemotherapy be $\geq 8$, which was also confirmed in our previous works to bring better overall survival (OS), DFS and metastasis-free survival (MFS) [11], analyses of survivals and toxicities were made in patients with total chemotherapy cycle $(\mathrm{TCC}) \leq 7$ and $\geq 8$, respectively.

\section{Methods}

\section{Patients}

A patient would be enrolled and retrospectively reviewed, if he or she had: (i) age $\leq 75$ years old; (ii) rectal cancer initially diagnosed in our hospital between Jan. 1st 2007 and Mar. 31st 2014; (iii) pretreatment stage of cII-III (cT34N0M0, cT1-4 N1-2 M0); (iv) completed records of NACRT and radical (R0) resection; (v) COD $\leq 780 \mathrm{mg} / \mathrm{m}^{2}$. COD was defined as the total dose of oxaliplatin received by a patient in neoadjuvant chemotherapy (NACT) and
ACT. The exclusion criteria included: (i) performance score of the Eastern Cooperative Oncology Group > 2; (ii) severe heart, lung, hepatic, kidney or hematopoietic dysfunctions unfit for chemotherapy or radiotherapy; (iii) past history of other cancerous diseases, chemotherapy or radiotherapy; (iv) DM before or during radiotherapy; (v) application of monoclonal antibody.

\section{Diagnostic work-up}

The pathological diagnosis was made through rectoscope. To decide pretreatment clinical stage, computed tomography (CT) of chest and abdomen, magnetic resonance imaging (MRI) of pelvis and endoscopic ultrasonography was performed for each patient. Wholebody bone scan was performed routinely to exclude bone metastasis. Positron emission tomography would be performed when suspicious DM was discovered by CT or MRI. Serum levels of carcinoembryonic antigen (CEA) and carbohydrate antigen 19-9 (CA19-9) were also tested before treatment.

\section{Treatment strategies}

Radiotherapy was performed with a 3-dimensional conformal or intensity-modulated technique, using a linear accelerator delivering an 8-MV photon beam. Target delineation was done on basis of the guidelines of the International Commission on Radiation Units and Measurements Reports 50 and 62. Total doses of 50 and 46 Gy were prescribed to macroscopic tumor (containing primary lesion and enlarged lymph nodes) and high-risk (containing pararectal, presacral, obturator, internal and common iliac) lymphatic drainage regions, respectively. Irradiation was performed in a conventional fractionation (2 Gy per fraction, 1 fraction per day, 5 days per week).

CAPEOX was used as the regimen of both NACT and ACT. The dose of capecitabine and oxaliplatin were 1000 $\mathrm{mg} / \mathrm{m}^{2}$ twice daily on Days $1-14$ and $130 \mathrm{mg} / \mathrm{m}^{2}$ on Day 1, repeated every 21 days. NACT was administered in 2 modes: (i) totally 2 cycles during radiotherapy; (ii) totally 4 cycles, including 1,2 and 1 cycles before, during and after radiotherapy, respectively. During radiotherapy, the dose of oxaliplatin was reduced to $100 \mathrm{mg} / \mathrm{m}^{2}$. After surgery, 4 cycles of ACT was performed. In ACT, singleagent capecitabine would take place of CAPEOX if: (i) COD reached $780 \mathrm{mg} / \mathrm{m}^{2}$; (ii) grade $3 / 4 \mathrm{PN}$ of the Common Terminology Criteria for Adverse Events (CTCAE) happened; (iv) grade 4 thrombocytopenia of CTCAE happened twice.

Radical surgery was scheduled 6-8 weeks after the last cycle of NACT, according to the standard of total mesorectal excision (TME). It contained complete removal of tumor-located rectal segment (with a 2-cm margin), mesorectum (with a 5-cm distal margin) and surrounding lymphovascular fatty tissue. A precise, 
sharp dissection was made within presacral space to ensure completeness of pelvic visceral fascia. If an adjacent organ was infiltrated by tumor, partial or total of it would be removed. When completeness of TME is doubted, a frozen section of resection margin was subjected to intraoperative pathologic examination. TME quality and resected specimens were examined by two pathologists specialized in gastrointestinal cancers. Macroscopically visible tumor block was embedded in paraffin and go through serial 3- to 5-mm full thickness sections. Pathologic evaluation contained infiltration and differentiation of tumor, numbers of examined and involved lymph nodes, and tumor regression grade (TRG).

Staging in this study was based on the TNM staging classification (8th edition) of the Union for International Cancer Control / American Joint Cancer Committee, both before treatment and after surgery. TME quality was assessed based on MECURY criteria [12]. TRG was based on Mandard's five-tier grading system [13], in which TRG 1-2 and 3-5 were defined as good and bad responders, respectively. Chemoradiotherapy-related acute toxicities were assessed based on the CTCAE criteria version 4.03.

\section{Follow-up}

In the first 3 years after treatment, the patients were followed up every 3-6 months through outpatient interview. Complete physical examination, thoraco-abdominal CT, pelvic MRI, serum CEA and CA19-9 evaluation were performed at every interview. Rectoscope and whole-body bone scan were performed annually. After the 3rd year, the patients were followed up every 6-12 months through outpatient interview or telephone, until death from rectal cancer (confirmed by death certificates) or Dec. 31st 2018, whichever came first.

\section{Endpoint definition}

OS was used as the primary endpoint in this study. It was defined as the percentage of patients who still survived after a defined duration from pathologic diagnosis. The secondary endpoints included DFS, recurrence-free survival (RFS) and MFS. These 3 endpoints were the percentages of patients without corresponding events after a defined duration, also from pathologic diagnosis. The events for RFS and MFS were local recurrence (LR) and DM, respectively. Death, LR and DM were all considered as the events for DFS. The patients were regarded censored if they had no event of death, LR or DM, or were lost to follow-up until Dec. 31st 2018. The percentages of patients with acute toxicities, PN and grade $3 / 4$ acute toxicities were also used as secondary endpoints. Acute toxicities referred to toxicities happening in the period of NACRT and ACT.

\section{Statistical analysis}

The eligible patients were divided by TCC, into the $\mathrm{TCC} \leq 7$ and $\geq 8$ groups. First, comparability and adverse effects between the patients receiving different COD were assessed in each group, through a Chi-square test. Next, predictive ability of COD on patients' survival was analyzed through a Kaplan-Meier approach-based univariate analysis. Last, a multivariate analysis based on COX proportional hazards model was made to confirm predictive independence of COD. Hazard ratios (HR) and 95\% confidence interval $(\mathrm{CI})$ were calculated for each factor during survival analysis.

The candidate prognosticators in univariate analysis included age, gender (male vs. female), anemia (yes vs. no), poor differentiation (yes vs. no), CEA, CA19-9, pretreatment clinical stage (cIII vs. cII), postsurgical pathologic stage (ypIII-II vs. ypI-0), TRG (5-3 vs. $2-1$ ) and COD. A factor would enter multivariate analysis when it exhibited statistical significance in univariate analysis. The cutoff value of age was the median age of the whole cohort. The definition of anemia was hemoglobin $<130$ $\mathrm{g} / \mathrm{L}$ for male and $<120 \mathrm{~g} / \mathrm{L}$ for female, in accordance with the standard of the World Health Organization [14]. The upper normal limit of serum CEA and CA199 were defined according to the standard of our hospital $(5.0 \mathrm{ng} / \mathrm{ml}$ and $35 \mathrm{U} / \mathrm{ml}$, respectively) [11]. The median CODs of the TCC $\leq 7$ and $\geq 8$ groups were used as their cutoff values of COD, respectively.

Statistical analysis was done by IBM SPSS Statistics 23.0 (IBM Co., Armonk, New York, US). A difference with a two-sided $P$ value of $<0.05$ was considered to be statistically significant. The whole procedure of this study was summarized as Fig. 1.

\section{Results}

\section{Patient enrollment}

From January 2007 to March 2014, there were totally 1127 consecutive patients diagnosed with untreated LARC in our hospital. Among these patients, 479 cases received NACRT followed by radical surgery. And finally 388 patients were eligible for analysis, after exclusion of 9 cases with age $>75$ years old, 13 cases with DM during treatment, 23 cases with prior malignancies, 4 cases with severe comorbidities, 20 cases with incomplete NACRT, and 22 cases receiving monoclonal antibody therapy. Among the 388 patients, 378 (97.4\%) and 10 (2.6\%) cases underwent complete (MECURY I) and nearly complete (MECURY II) mesorectal excision. There was no incomplete (MECURY III) mesorectal excision.

\section{Baseline characteristics}

The median age of the patients was 55 (range, 15 to 75) years old. Thus, the cutoff value of age was 55 years old. When grouped by TCC, there were 169 and 219 patients 


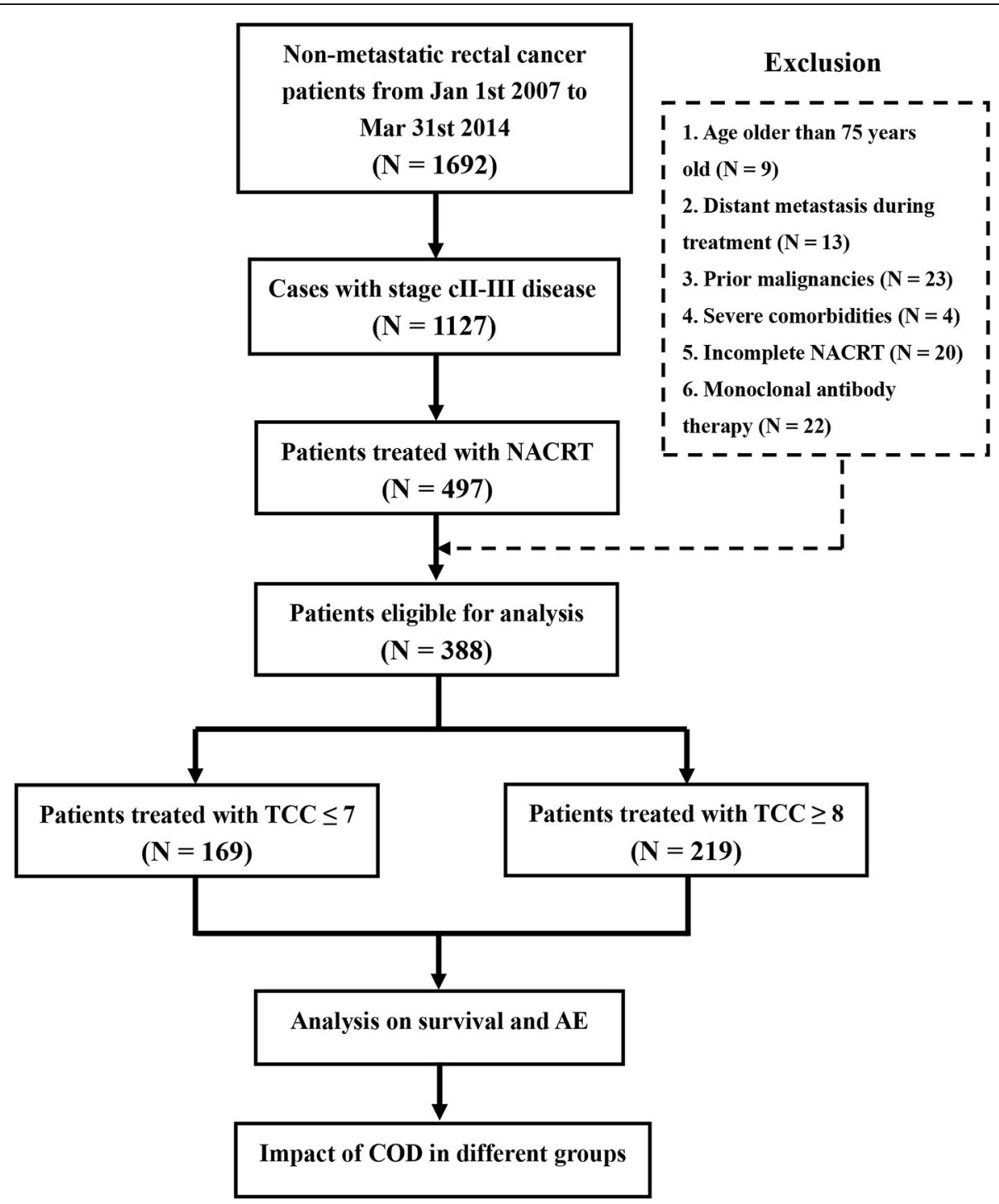

Fig. 1 Procedure of enrollment and analysis. Abbrevations: NACRT, neoadjuvant chemoradiotherapy; TCC, total chemotherapy cycle; COD, cumulative oxaliplatin dose; $\mathrm{AE}$, adverse effect

in the $\mathrm{TCC} \leq 7$ and $\geq 8$ groups, respectively. In the TCC $\geq 8$ group, 3 (1.4\%) cases received 10 cycles of chemotherapy (6 cycles of CAPEOX and 4 cycles of capecitabine). The other 216 (98.6\%) cases all received 8 cycles. In the TCC $\leq 7$ group, 111 (65.9\%), 45 (26.6\%) and $13(7.7 \%)$ cases received 6,4 and 2 cycles, respectively. In these 2 group, the median CODs were 460 (range, 200-720) and 720 (range, 200-780) $\mathrm{mg} / \mathrm{m}^{2}$, which were also used as cutoff values of COD for subsequent analysis.

The baseline clinical features of the patients were showed in Table 1, including age, gender, anemia, tumor differentiation, CEA, CA19-9 and clinical stage. No difference was observed between the patients receiving different COD, in either the TCC $\leq 7$ or $\geq 8$ group.

\section{Adverse events}

In the TCC $\leq 7$ group, the patients treated with COD $\geq 460 \mathrm{mg} / \mathrm{m}^{2}$ had a higher incidence of acute toxicities, compared with those treated with COD $<460 \mathrm{mg} / \mathrm{m}^{2}$ ( $70.8 \%$ vs. $38.4 \%, P<0.001)$. However, there was no difference in incidence of $\mathrm{PN}$ or grade $3 / 4$ acute toxicities between patients receiving different CODs (Fig. 2a).

In the TCC $\geq 8$ group, no difference was seen in incidence of acute toxicities, PN or grade $3 / 4$ acute toxicities, between the patients receiving COD $\geq 720 \mathrm{mg} / \mathrm{m}^{2}$ and those treated with COD $<720 \mathrm{mg} / \mathrm{m}^{2}$ (Fig. 2b).

\section{Survival outcomes}

Results of univariate analysis were showed in Fig. 3. In the TCC $\leq 7$ group, CA19-9 $\geq 35 \mathrm{U} / \mathrm{ml}$, stage ypIII-II 
Table 1 Clinical characteristics of the eligible patients

\begin{tabular}{|c|c|c|c|c|c|c|}
\hline \multirow[t]{2}{*}{ Characteristics } & \multicolumn{2}{|l|}{ TCC $\leq 7(\boldsymbol{N}=169)$} & \multirow[b]{2}{*}{$\boldsymbol{P}$ value } & \multicolumn{2}{|l|}{ TCC $\geq 8(\boldsymbol{N}=219)$} & \multirow[b]{2}{*}{$\boldsymbol{P}$ value } \\
\hline & $\begin{array}{l}\mathrm{COD}<460 \mathrm{mg} / \mathrm{m}^{2} \\
(\boldsymbol{N}=73)\end{array}$ & $\begin{array}{l}\mathrm{COD} \geq 460 \mathrm{mg} / \mathrm{m}^{2} \\
(\boldsymbol{N}=96)\end{array}$ & & $\begin{array}{l}\mathrm{COD}<720 \mathrm{mg} / \mathrm{m}^{2} \\
(\boldsymbol{N}=90)\end{array}$ & $\begin{array}{l}C O D \geq 720 \mathrm{mg} / \mathrm{m}^{2} \\
(\boldsymbol{N}=129)\end{array}$ & \\
\hline \multicolumn{7}{|l|}{ Age / years old } \\
\hline$\geq 55$ & $44(60.3 \%)$ & $55(57.3 \%)$ & 0.697 & 45 (50.0\%) & 51 (39.5\%) & 0.125 \\
\hline$<55$ & $29(39.7 \%)$ & $41(42.7 \%)$ & & 45 (50.0\%) & $78(60.5 \%)$ & \\
\hline \multicolumn{7}{|l|}{ Gender } \\
\hline Male & $46(63.0 \%)$ & $71(74.0 \%)$ & 0.127 & $63(70.0 \%)$ & $78(60.5 \%)$ & 0.147 \\
\hline Female & $27(37.0 \%)$ & $25(26.0 \%)$ & & $27(30.0 \%)$ & $51(39.5 \%)$ & \\
\hline \multicolumn{7}{|l|}{ Anemia } \\
\hline Yes & $26(35.6 \%)$ & $27(28.1 \%)$ & 0.298 & $33(36.7 \%)$ & 35 (27.1\%) & 0.134 \\
\hline No & 47 (64.4\%) & 69 (71.9\%) & & $57(63.3 \%)$ & 94 (72.9\%) & \\
\hline \multicolumn{7}{|l|}{ Differentiation } \\
\hline Poor & $11(16.7 \%)$ & $12(12.9 \%)$ & 0.506 & 8 (8.9\%) & $20(15.5 \%)$ & 0.149 \\
\hline Moderate-good & $62(83.3 \%)$ & 84 (87.1\%) & & 82 (91.1\%) & 109 (84.5\%) & \\
\hline \multicolumn{7}{|l|}{ CEA / ng/ml } \\
\hline$\geq 5$ & $36(49.3 \%)$ & 39 (46.0\%) & 0.260 & $42(46.7 \%)$ & $56(43.4 \%)$ & 0.634 \\
\hline$<5$ & $37(50.7 \%)$ & $57(54.0 \%)$ & & 48 (53.3\%) & 73 (56.6\%) & \\
\hline \multicolumn{7}{|l|}{ CA19-9 / U/ml } \\
\hline$\geq 35$ & $18(24.7 \%)$ & $15(15.6 \%)$ & 0.581 & $11(12.2 \%)$ & $23(17.8 \%)$ & 0.260 \\
\hline$<35$ & $55(75.3 \%)$ & 81 (84.4\%) & & 79 (87.8\%) & $106(82.2 \%)$ & \\
\hline \multicolumn{7}{|l|}{ Clinical stage } \\
\hline cllI & 47 (64.4\%) & $73(76.0 \%)$ & 0.098 & 71 (78.9\%) & $112(86.8 \%)$ & 0.119 \\
\hline cll & $26(35.6 \%)$ & $23(24.0 \%)$ & & $19(21.1 \%)$ & $17(13.2 \%)$ & \\
\hline
\end{tabular}

Abbreviations: TCC Total chemotherapy cycle, COD Cumulative oxaliplatin dose, CEA Carcinoembryonic antigen, CA19-9 Carbohydrate antigen 19-9

disease, TRG $5-3$ and COD $<460 \mathrm{mg} / \mathrm{m}^{2}$ were risk factors of poorer OS ( $P$ values were $0.008,0.002,0.031$ and $0.021)$, MFS ( $P$ values were $0.009,0.004,0.039$ and $0.024)$ and DFS ( $P$ values were $0.023,0.002,0.031$ and 0.037). Poor differentiation was the sole risk factor of poorer RFS $(P=0.027)$. And anemia was also a risk factor of poorer MFS $(P=0.029)$.

In the TCC $\geq 8$ group, stage ypIII-II disease and TRG 5-3 were risk factors of poorer OS $(P$ values were 0.011 and 0.021$)$, MFS ( $P$ values were 0.002 and 0.005$)$ and DFS $(P$ values were 0.003 and 0.006$)$. COD $(<720$ vs. $\geq 720$ $\mathrm{mg} / \mathrm{m}^{2}$ ) failed to be a predictor of OS, RFS, MFS or DFS.

In multivariate analysis on the $\mathrm{TCC} \leq 7$ group (Table 2), postsurgical pathologic stage and COD maintained as independent predictors of OS, MFS and DFS. The HRs of postsurgical pathologic stage (ypIII-II vs. ypI-0) were 4.237 (95\% CI, 1.252-14.29), 2.747 (95\% CI, 1.068-7.812) and 2.801 (95\% CI, 1.053-7.462), respectively. And the HRs of COD (<460 vs. $\geq 460 \mathrm{mg} / \mathrm{m}^{2}$ ) were 1.972 (95\% CI, 1.106-3.521), 1.763 (95\% CI, 1.0622.933 ) and 1.637 (95\% CI, 1.110-2.688), respectively. Survival curves of patients divided by COD were showed in Fig. 4. Both postsurgical pathologic stage and TRG failed to be an independent predictor of OS, MFS or DFS, in the TCC $\geq 8$ group (See supplementary materials, Table S1).

\section{Discussion}

Fluorouracil, or its derivative capecitabine, is now the basis of chemotherapy for LARC. Combining fluorouracil or capecitabine to preoperative radiotherapy has been proven to improve local control, due to radiosensitizing effects of these 2 agents. However, no improved OS is brought by concomitant chemoradiotherapy $[15,16]$. Oxaliplatin is another radiosensitizing agent that emerges to be more effective than fluorouracil [17]. And it has been demonstrated by clinical studies to improve DFS, and even OS of colon cancer, when added to fluorouracil-based chemotherapy as a constituent [18, 19]. Therefore, it could naturally be inferred that when combined with fluorouracil or capecitabine, oxaliplatin might ameliorate long-term outcome of LARC as well.

The earliest randomized trial comparing chemotherapy regimens with or without oxaliplatin in LARC was 

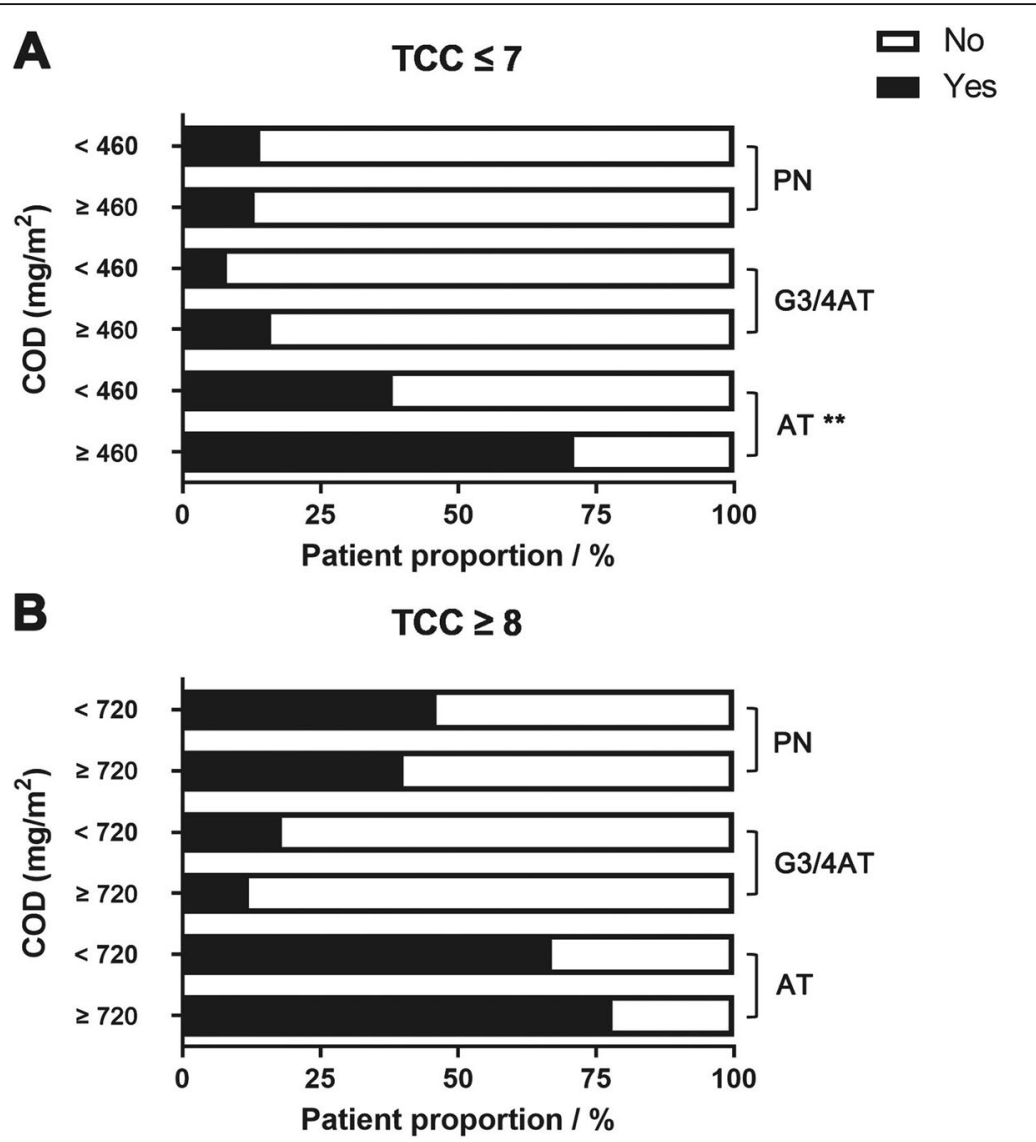

Fig. 2 Adverse events in patients treated with different cumulative oxaliplatin doses. a: total chemotherapy cycle $\leq 7$. b: total chemotherapy cycle 28. Abbreviations: COD, cumulative oxaliplatin dose; TCC, total chemotherapy cycle; AT, acute toxicities; G3/4AT, grade 3/4 acute toxicities; PN, peripheral neuropathy. ${ }^{* *} P<0.01$

the STAR-01 trial, in which combination of oxaliplatin and fluorouracil failed to improve tumor response [6]. In the following ACCORD 12 and NSABP R-04 trials, no improvement of 3- or 5- year DFS or OS was achieved through adding oxaliplatin to capecitabine or fluorouracil, either $[7,8]$. The CAO/ARO/AIO-04 trial was the first study to support addition of oxaliplatin to fluorouracil and leucovorin (FOLFOX). This regimen increased 3-year DFS from 71.2 to $75.9 \%$ [9]. The FOWARC trial reported that FOLFOX regimen could also elevate pCR (14.0 to $27.5 \%)$ and downstaging (37.1 to $56.4 \%$ ) rates of patients [20]. Similarly, the ADORE trial and a trial by Jiao et al. showed superiority of FOLFOX regimen in reducing DM and ameliorating DFS at 3 years [21, 22]. Meta-analyses provided further evidences for application of oxaliplatin. De Felice et al., found oxaliplatin to decrease risk of DM $(H R=0.76)$, through analysis of 4 trials [23]. And Zheng et al. analyzed data of 8 trails to report that oxaliplatin could brought a better DFS [24].

It was noteworthy that the COD in the STAR-01, ACCORD 12 and NSABP R-04 trials (360, 250 and
$250 \mathrm{mg} / \mathrm{m}^{2}$ ) were much less than that in the $\mathrm{CAO} /$ ARO/AIO-04, FOWARC, ADORE trials and the trial by Jiao et al. $\left(1000,1020,680\right.$, and $\left.750-920 \mathrm{mg} / \mathrm{m}^{2}\right)$ $[6-9,20-22]$. Considering that TCC $\geq 8$ was an independent predictor of better prognosis in our previous works [11], we speculated that enough COD might be necessary to attain ideal DM control and survival improvement, especially for patients receiving insufficient TCC $(\leq 7)$. Hence, survival analyses stratified by TCC was performed in this study, to test our hypothesis. As expected, COD of $460-720 \mathrm{mg} / \mathrm{m}^{2}$ appeared as an independent predictor of better OS, MFS and DFS in the TCC $\leq 7$ group. But in the TCC $\geq 8$ group, COD of $720-780 \mathrm{mg} / \mathrm{m}^{2}$ failed to bring any benefit of OS, RFS, MFS or DFS. Currently, a considerable number of patients do not receive ACT, because of its uncertain necessity in LARC treated with NACRT $[25,26]$. For these patients and those refusing or intolerable for ACT, NACT with a combination regimen containing oxaliplatin of $\geq 460 \mathrm{mg} / \mathrm{m}^{2}$ might be needed. Our study provided findings illuminating to conduct individualized treatment and clinical trials. 


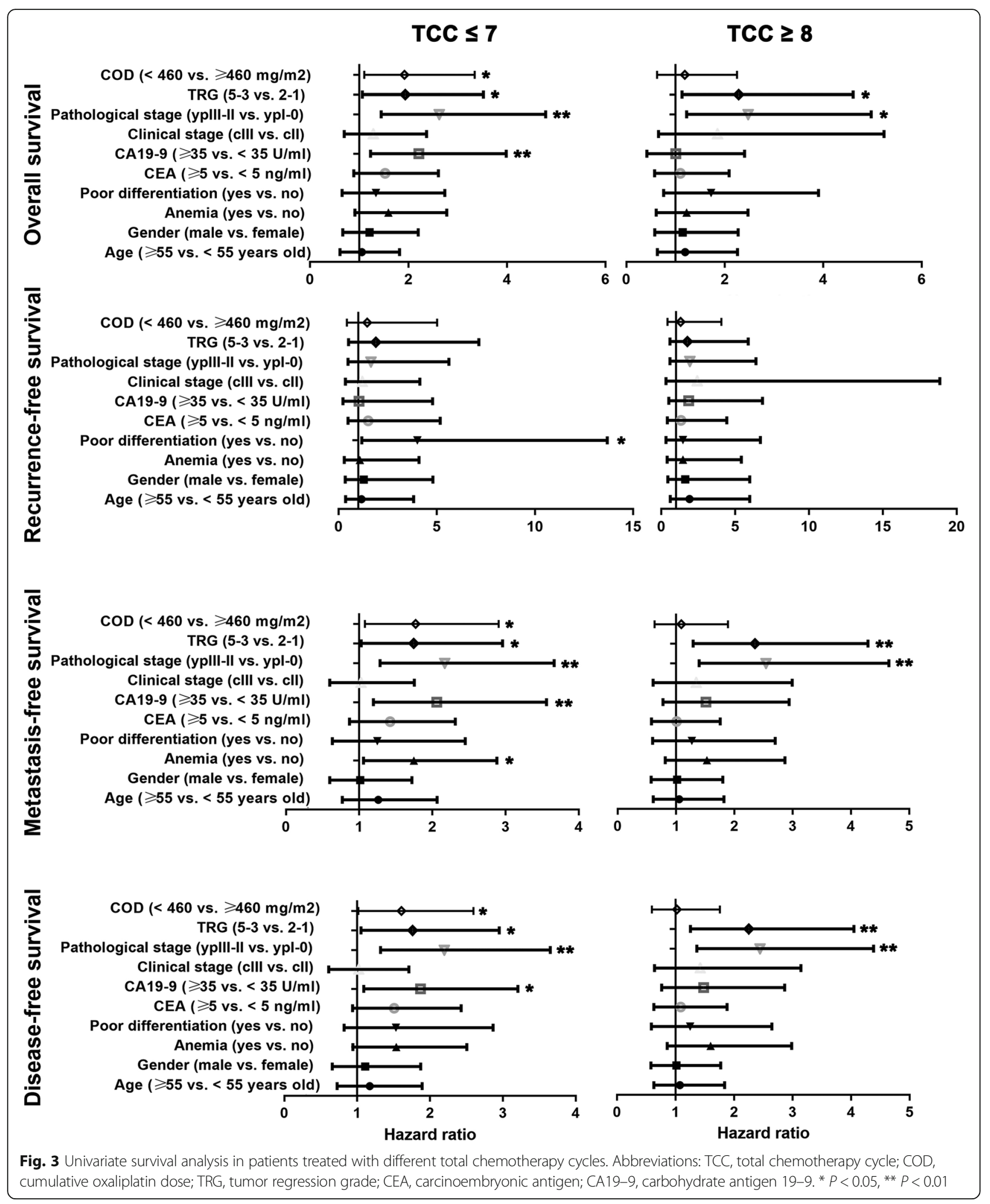

Raised risk of toxicities from oxaliplatin, especially severe $\mathrm{PN}$, is another concern. A trial by Schmoll et al. showed that compared with fluorouracil plus leucovorin,
CAPEOX regimen brought more grade $3 / 4$ acute $\mathrm{PN}$ $(11 \%$ vs. $<1 \%)$ without increasing other severe toxicities [27]. In the NSABP C-07 trial, the most common grade 
Table 2 Multivariate survival analysis in patients treated with total chemotherapy cycle $\leq 7$

\begin{tabular}{|c|c|c|c|}
\hline Factors of OS & $P$ value & HR & $95 \% \mathrm{Cl}$ \\
\hline Pathological stage (ypl|I-II vs. ypl-0) & $0.020^{*}$ & 4.237 & $1.252-14.29$ \\
\hline $\operatorname{COD}\left(<460 \mathrm{vs} . \geq 460 \mathrm{mg} / \mathrm{m}^{2}\right)$ & $0.021^{*}$ & 1.972 & $1.106-3.521$ \\
\hline CA19-9 ( $\geq 35$ vs. $<35 \mathrm{U} / \mathrm{ml}$ ) & 0.247 & 1.448 & $0.774-2.709$ \\
\hline TRG (5-3 vs. 2-1) & 0.316 & 1.842 & $0.558-6.077$ \\
\hline Factors of MFS & $P$ value & HR & $95 \% \mathrm{Cl}$ \\
\hline Pathological stage (ypll|-II vs. ypl-0) & $0.048^{*}$ & 2.747 & $1.068-7.812$ \\
\hline $\operatorname{COD}\left(<460\right.$ vs. $\left.\geq 460 \mathrm{mg} / \mathrm{m}^{2}\right)$ & $0.028^{*}$ & 1.763 & $1.062-2.933$ \\
\hline CA19-9 ( $\geq 35$ vs. $<35 \mathrm{U} / \mathrm{ml})$ & 0.161 & 1.503 & $0.850-2.656$ \\
\hline Anemia (yes vs. no) & 0.114 & 1.514 & $0.906-2.530$ \\
\hline TRG (5-3 vs. $2-1)$ & 0.427 & 1.530 & $0.536-4.369$ \\
\hline Factors of DFS & $P$ value & HR & $95 \% \mathrm{Cl}$ \\
\hline Pathological stage (ypll|-II vs. ypl-0) & $0.039^{*}$ & 2.801 & $1.053-7.462$ \\
\hline $\operatorname{COD}\left(<460 \mathrm{vs} . \geq 460 \mathrm{mg} / \mathrm{m}^{2}\right)$ & $0.041^{*}$ & 1.637 & $1.110-2.688$ \\
\hline CA19-9 ( $\geq 35$ vs. $<35 \mathrm{U} / \mathrm{ml})$ & 0.264 & 1.381 & $0.783-2.438$ \\
\hline TRG (5-3 vs. $2-1)$ & 0.499 & 1.398 & $0.529-3.690$ \\
\hline
\end{tabular}

* $P<0.05$. Abbreviations: OS Overall survival, MFS Metastasis-free survival, DFS Disease-free survival, $H R$ Hazard ratio, $\mathrm{Cl}$ Confidence interval, $C O D$ Cumulative oxaliplatin dose, CA19-9 Carbohydrate antigen 19-9, TRG Tumor regression grade

3/4 acute toxicities were diarrhea, nausea and vomiting, whose incidences was not affected by oxaliplatin. FOLFOX regimen merely caused a higher incidence of grade $2+$ PN (30.4\% vs. 3.6\%) [17]. Oppositely, in the STAR-01 trial, oxaliplatin resulted in more grade $3 / 4$ acute diarrhea $(15 \%$ vs. $4 \%)$ and asthenia ( $3 \%$ vs. $0 \%$ ) but not grade
3/4 PN [6]. Although having a high COD, the CAO/ $\mathrm{ARO} / \mathrm{AIO}-04$ trial reported that patients receiving regimens with and without oxaliplatin underwent similar acute toxicities, including PN [9]. In our study, 256 out of the 388 patients $(66.0 \%)$ suffered from acute toxicities, among which $20.3 \%$ were of grade $3 / 4$. PN was seen in $32.2 \%$ of the patients and all of grade $1 / 2$. Comparison of toxicities revealed that in the $\mathrm{TCC} \leq 7$ group, COD $\geq 460 \mathrm{mg} / \mathrm{m}^{2}$ was associated with a higher incidence of overall acute toxicities, rather than $\mathrm{PN}$ or grade $3 / 4$ toxicities. Interestingly, COD of $\geq 720 \mathrm{mg} / \mathrm{m}^{2}$ did not lead to more chemoradiotherapy-related toxicities in the TCC $\geq$ 8 group. Our results was in accordance with those of the $\mathrm{CAO} / \mathrm{ARO} / \mathrm{AIO}-04$ trial. In other words, oxaliplaitn could be safe when COD was $\leq 780 \mathrm{mg} / \mathrm{m}^{2}$.

Indeed, there were 2 major limitations in this study. First, the retrospective nature of this study might bring some biases, like selection biases. But comparison of baseline characteristics showed that the patients with different CODs were comparable. And multivariate survival analysis could control biases to some extent. Second, its sample size was not large enough, for NACRT became mainstream treatment for LARC just from the year of 2012, even in the developed countries [28]. So we proposed that our results be further validated by prospective randomized controlled trials before popularization.

\section{Conclusions}

For LARC treated with TCC $\leq 7$, oxaliplatin of $\geq 460 \mathrm{mg}$ / $\mathrm{m}^{2}$ might be needed to improve survival, though it might resulted in more mild acute toxicities. This

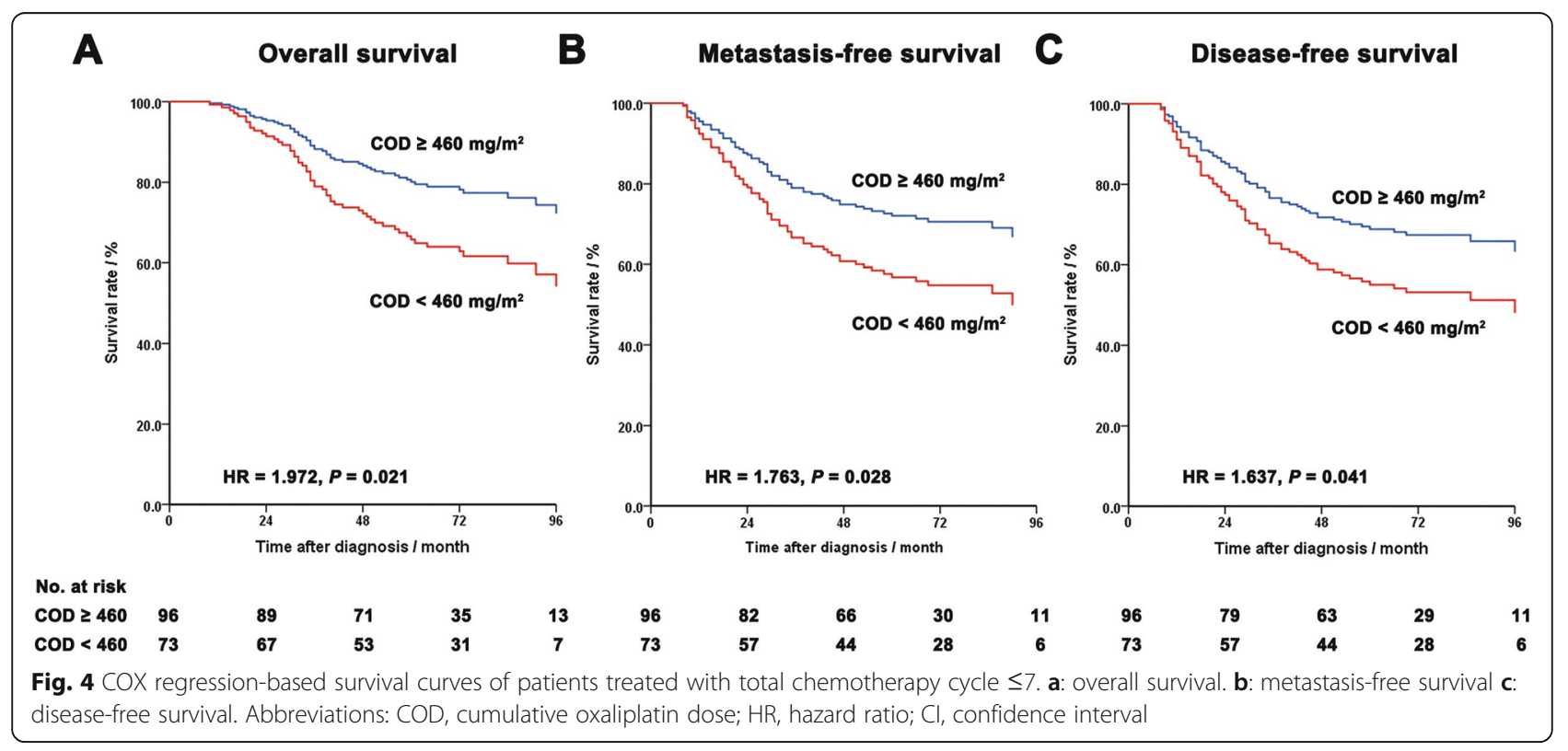


finding is instructive though further validation is recommended.

\section{Supplementary information}

Supplementary information accompanies this paper at https://doi.org/10. 1186/s12885-020-06988-X.

Additional file 1: Table S1. Multivariate survival analysis in patients treated with total chemotherapy cycle $\geq 7$.

\section{Abbreviations}

LARC: Locally advanced rectal cancer; NACRT: Neoadjuvant chemoradiotherapy; ACT: Adjuvant chemotherapy; DM: Distant metastasis; CAPEOX: Capecitabine plus oxaliplatin; pCR: pathological complete response; DFS: Disease-free survival; COD: Cumulative oxaliplatin dose; PN: Peripheral neuropathy; OS: Overall survival; MFS: Metastasis-free survival; TCC: Total chemotherapy cycle; NACT: Neoadjuvant chemotherapy; CT: Computed tomography; MRI: Magnetic resonance imaging; CEA: Carcinoembryonic antigen; CA19-9: Carbohydrate antigen 19-9; CTCAE: Common Terminology Criteria for Adverse Events; TME: Total mesorectal excision; TRG: Tumor regression grade; RFS: Recurrence-free survival; LR: Local recurrence; HR: Hazard ratios; Cl: Confidence interval; FOLFOX: Oxalipaltin, fluorouracil plus leucovorin

\section{Acknowledgments}

Not applicable.

\section{Authors' contributions}

Conception: WJY, YHG; methodology design: HC, YLT; data collection and assembly: WJ, CC, SLL; data analysis: HC, YLT, WJ, CC, SLL; data interpretation: HC, YLT; manuscript writing: all authors; content guarantor: WJY, YHG. All authors have read and approved the manuscript.

\section{Funding}

This study was supported by the Guangdong Basic and Applied Basic Research Foundation, China; Grant numbers: 2020A1515010037 and 2020A1515011286. The funding sources had no role in the study design, data collection, analysis, interpretation, or writing of the manuscript.

\section{Availability of data and materials}

The datasets used and/or analyzed during the current study are available from the corresponding authors on reasonable request.

\section{Ethics approval and consent to participate}

This study was approved by the Institutional Review Board of the Sun Yatsen University Cancer Center. Written informed consents were obtained from all patients to receive chemoradiotherapy and surgery. Because this is a retrospective study, we did not obtain written informed consents from all patients for participating in this study. Administrative permissions to access the raw data could be obtained from the corresponding authors (WJY and YHG). The data used in this study was anonymised before its use.

\section{Consent for publication}

Not applicable.

\section{Competing interests}

The authors declare that they have no competing interests.

\section{Author details}

'Department of Radiation Oncology, Sun Yat-sen University Cancer Center, Guangzhou, China. ${ }^{2}$ State Key Laboratory of Oncology in South China, Collaborative Innovation Center for Cancer Medicine, Guangzhou, China. ${ }^{3}$ Department of Colorectal Surgery, Sun Yat-sen University Cancer Center, Guangzhou, China.
Received: 10 August 2019 Accepted: 21 May 2020

Published online: 01 June 2020

\section{References}

1. Chen W, Sun K, Zheng R, et al. Cancer incidence and mortality in China, 2014. Chin J Cancer Res. 2018;30(1):1-12.

2. Pang Y, Kartsonaki C, Guo Y, et al. Diabetes, plasma glucose and incidence of colorectal cancer in Chinese adults: a prospective study of 0.5 million people. J Epidemiol Community Health. 2018:72(10):919-25.

3. Smith CA, Kachnic LA. Evolving treatment paradigm in the treatment of locally advanced rectal Cancer. J Natl Compr Cancer Netw. 2018;16(7): 909-15.

4. Fokas E, Ströbel P, Fietkau R, et al. German Rectal Cancer Study Group. Tumor Regression Grading After Preoperative Chemoradiotherapy as a Prognostic Factor and Individual-Level Surrogate for Disease-Free Survival in Rectal Cancer. J Natl Cancer Inst. 2017;109(12):djx095.

5. Roselló S, Papaccio F, Roda D, et al. The role of chemotherapy in localized and locally advanced rectal cancer: a systematic revision. Cancer Treat Rev. 2018;63:156-71.

6. Aschele $\mathrm{C}$, Cionini $\mathrm{L}$, Lonardi $\mathrm{S}$, et al. Primary tumor response to preoperative chemoradiation with or without oxaliplatin in locally advanced rectal cancer: pathologic results of the STAR-01 randomized phase III trial. J Clin Oncol. 2011;29(20):2773-80.

7. Gérard JP, Azria D, Gourgou-Bourgade S, et al. Clinical outcome of the ACCORD 12/0405 PRODIGE 2 randomized trial in rectal cancer. J Clin Oncol. 2012:30(36):4558-65.

8. Allegra CJ, Yothers G, O'Connell MJ, et al. Neoadjuvant 5-FU or Capecitabine Plus Radiation With or Without Oxaliplatin in Rectal Cancer Patients: A Phase III Randomized Clinical Trial. J Natl Cancer Inst. 2015;107(11):djv248.

9. Rödel C, Graeven U, Fietkau R, et al. German rectal Cancer study group. Oxaliplatin added to fluorouracil-based preoperative chemoradiotherapy and postoperative chemotherapy of locally advanced rectal cancer (the German CAO/ARO/AIO-04 study): final results of the multicentre, open-label, randomised, phase 3 trial. Lancet Oncol. 2015;16(8):979-89.

10. Sereno M, Gutiérrez-Gutiérrez G, Rubio JM, et al. Genetic polymorphisms of SCN9A are associated with oxaliplatin-induced neuropathy. BMC Cancer. 2017;17(1):63.

11. Chang $H, Y u$ X, Chen $K$, et al. Prognostic value of the cycle number of perioperative chemotherapy in Locoregionally advanced rectal Cancer: a propensity score matching analysis. J Cancer. 2018;9(23):4346-54.

12. Herzog T, Belyaev $\mathrm{O}$, Chromik AM, et al. TME quality in rectal cancer surgery. Eur J Med Res. 2010;15(7):292-6.

13. Trakarnsanga A, Gönen $M$, Shia J, et al. Comparison of tumor regression grade systems for locally advanced rectal cancer after multimodality treatment. J Natl Cancer Inst. 2014;106(10):dju248.

14. World Health Organization. The global prevalence of Anaemia in 2011. Geneva Switzerland WHO. 2011;126(11):5409-18.

15. McCarthy K, Pearson K, Fulton R, Hewitt J. Pre-operative chemoradiation for non-metastatic locally advanced rectal cancer. Cochrane Database Syst Rev. 2012;12:CD008368.

16. Zou XC, Wang QW, Zhang JM. Comparison of 5-FU-based and Capecitabine-based Neoadjuvant Chemoradiotherapy in patients with rectal Cancer: a meta-analysis. Clin Colorectal Cancer. 2017:16(3):e123-39.

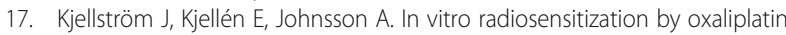
and 5-fluorouracil in a human colon cancer cell line. Acta Oncol. 2005:44(7): 687-93.

18. Yothers G, O'Connell MJ, Allegra CJ, et al. Oxaliplatin as adjuvant therapy for colon cancer: updated results of NSABP C-07 trial, including survival and subset analyses. J Clin Oncol. 2011:29(28):3768-74.

19. André T, de Gramont A, Vernerey D, et al. Adjuvant fluorouracil, Leucovorin, and Oxaliplatin in stage II to III Colon Cancer: updated 10-year survival and outcomes according to BRAF mutation and mismatch repair status of the MOSAIC study. J Clin Oncol. 2015;33(35):4176-87.

20. Deng $Y$, Chi $P$, Lan $P$, et al. Modified FOLFOX 6 with or without radiation versus fluorouracil and Leucovorin with radiation in Neoadjuvant treatment of locally advanced rectal Cancer: initial results of the Chinese FOWARC multicenter, open-label, randomized three-arm phase III trial. J Clin Oncol. 2016:34(27):3300-7.

21. Hong YS, Nam BH, Kim KP, et al. Oxaliplatin, fluorouracil, and leucovorin versus fluorouracil and leucovorin as adjuvant chemotherapy for locally advanced rectal cancer after preoperative chemoradiotherapy (ADORE): an 
open-label, multicentre, phase 2, randomised controlled trial. Lancet Oncol. 2014;15(11):1245-53.

22. Jiao D, Zhang R, Gong Z, et al. Fluorouracil-based preoperative chemoradiotherapy with or without oxaliplatin for stage II/III rectal cancer: a 3-year follow-up study. Chin J Cancer Res. 2015;27(6):588-96.

23. De Felice F, Benevento I, Magnante AL, et al. Clinical benefit of adding oxaliplatin to standard neoadjuvant chemoradiotherapy in locally advanced rectal cancer: a meta-analysis: Oxaliplatin in neoadjuvant treatment for rectal cancer. BMC Cancer. 2017;17(1):325.

24. Zheng J, Feng $X$, Hu W, et al. Systematic review and meta-analysis of preoperative chemoradiotherapy with or without oxaliplatin in locally advanced rectal cancer. Medicine (Baltimore). 2017;96(13):e6487.

25. Breugom AJ, Swets M, Bosset JF, et al. Adjuvant chemotherapy after preoperative (chemo)radiotherapy and surgery for patients with rectal cancer: a systematic review and meta-analysis of individual patient data. Lancet Oncol. 2015;16(2):200-7.

26. Dossa F, Acuna SA, Rickles AS, et al. Association between adjuvant chemotherapy and overall survival in patients with rectal Cancer and pathological complete response after Neoadjuvant chemotherapy and resection. JAMA Oncol. 2018:4(7):930-7.

27. Schmoll HJ, Cartwright T, Tabernero J, et al. Phase III trial of capecitabine plus oxaliplatin as adjuvant therapy for stage III colon cancer: a planned safety analysis in 1,864 patients. J Clin Oncol. 2007;25(1):102-9.

28. Sineshaw HM, Jemal A, Thomas CR Jr, et al. Changes in treatment patterns for patients with locally advanced rectal cancer in the United States over the past decade: an analysis from the National Cancer Data Base. Cancer. 2016;122(13):1996-2003.

\section{Publisher's Note}

Springer Nature remains neutral with regard to jurisdictional claims in published maps and institutional affiliations.

Ready to submit your research? Choose BMC and benefit from:

- fast, convenient online submission

- thorough peer review by experienced researchers in your field

- rapid publication on acceptance

- support for research data, including large and complex data types

- gold Open Access which fosters wider collaboration and increased citations

- maximum visibility for your research: over $100 \mathrm{M}$ website views per year

At BMC, research is always in progress.

Learn more biomedcentral.com/submissions 